\title{
Mid-Right Coronary Artery Conduit
}

National Cancer Institute

\section{Source}

National Cancer Institute. Mid-Right Coronary Artery Conduit. NCI Thesaurus. Code C102329.

The section of the right coronary artery between the right ventricular artery and the acute marginal artery. 